\title{
Performance comparison between variants PID controllers and unity feedback control system for the response of the angular position of the DC motor
}

\author{
Mustafa A. Mhawesh \\ Al-Furat Al-Awsat Technical University, Iraq
}

\begin{tabular}{l}
\hline Article Info \\
\hline Article history: \\
Received May 11, 2020 \\
Revised Aug 7, 2020 \\
Accepted Aug 17, 2020
\end{tabular}

Keywords:

DC motor modeling

I-PD controller

PID controller

PI-D controller

Ziegler and Nichols method

\begin{abstract}
This paper proposed a detailed study for the response of angular position of the rotor of a DC motor. It is a comparative analysis to the behavior of the DC motor when the motor is alone and when it is with controllers. Furthermore, a comparison between the responses of controllers themselves. A conventional PID controller which was tuned by using Ziegler and Nichols method was proposed in this paper. Also, Modification PID controllers were proposed in this paper. The modification PID controllers are PI-D controller and I-PD controller. Mathematical calculations were done to get the transfer functions for the DC motor and the controllers. Time domain specifications and figures were obtained for each case by using Matlab program. The obtained results were summarized in tables. This paper determined which the controller is the best one depending on the obtained figures and the time domain specifications.
\end{abstract}

This is an open access article under the CC BY-SA license.

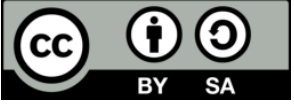

Corresponding Author:

Mustafa A. Mhawesh,

Al-Furat Al-Awsat Technical University,

Kufa, Najaf, Iraq.

Email: mustafaazzam@atu.edu.iq

\section{INTRODUCTION}

DC motors are commonly used in many uses because it has simplicity and accuracy in control characteristics. It is used in robotic arms, electric trains and cars, steel rolling mills, drones, conveyor belts, and cranes [1-7]. There are a lot of researches were achieved on the speed control of DC motors. Most of them used the PID controller to set the DC motor speed [3, 8, 9]. PID controller is combined from proportional (P), Integral (I), and derivative (D) controllers. Therefore, it is named three terms controllers. When PID controller is used, the response will be good, reliable, and robust [8, 10-12]. The P controller of PID is used to decrease the disturbance effects on the system output. The (I) controller of PID is used to remove steady-state error. The D controller of PID is used to weaken the dynamic response makes the system more stable [2]. PID transfer function is

$$
\mathrm{PID}=k_{p}\left(1+\frac{1}{T_{i} S}+T_{d} S\right)
$$

The authors of [2] used conventional proportional integral derivative, genetic algorithm, GA, to modify the PID elements, and a self-tuning fuzzy PID controller to regulate the speed of BLDC motor. The authors of [8] used conventional PID and PI-D control to control a fly-by-wire flight. The authors of [13] used PID controller with friction compensator to fix the exactly angular position of DC geared motor. Moreover, they used the UNO Arduino microcontroller to control the voltage of the brushed Namiki direct 
current motor. The authors of [14] used PID controller to govern the angular position of DC motor attached to a hydraulic pump valve. The author of [15] used PID and FLC controllers to control shunt DC motor. The authors of [16] presented a comparison for the ways of tuning the PID to regulate the speed of direct current motor. The authors of [17] used the PID to control DC motor when the load is variable. The authors of [18] used a tuned PID to set the speed of PMDCM. The authors of [19] used different controllers to govern the DC motor. The PID is one of them. The authors of [20] used the Z-N method to tune PI/PID controllers for incorporating fractional-order dynamics in an existing DC motor control system. Variants PID controllers are proposed in this paper to control the angular position of the rotor of a DC motor. Ziegler and Nichols second method (Z-N $2^{\text {nd }}$ method) is applied to adjust the elements of PID controller as shown in Table 1 and Figure 1.

Table 1. Z-N $2^{\text {nd }}$ method tuning rule depending on critical gain $K_{c r}$ and critical period $P_{c r}[18,21]$

\begin{tabular}{cccc}
\hline Type of Controller & $k_{p}$ & $T_{i}$ & $T_{d}$ \\
\hline P & $0.5 k_{c r}$ & $\infty$ & 0 \\
PI & $0.45 k_{c r}$ & $\frac{1}{1.2} P_{c r}$ & 0 \\
& & \\
PID & $0.6 k_{c r}$ & $0.5 P_{c r}$ & $0.125 P_{c r}$ \\
\hline
\end{tabular}

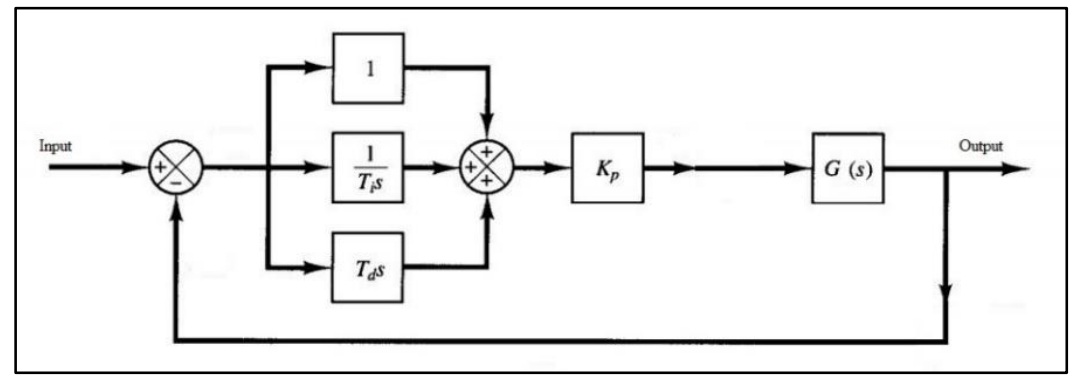

Figure 1. PID controller [21]

Transfer function of it $=k_{p}\left(1+\frac{1}{T_{i} S}+T_{d} s\right) * \frac{\mathrm{G}}{\left[1+\left[k_{p}\left(1+\frac{1}{T_{i} s}+T_{d} s\right)\right] \mathrm{G}\right.}$

PI-D controller is rearrangement the connection of PID elements. The D part of the PID is connected with the feedback path. It is used to prevent the effectiveness of the set-point kick phenomenon $[8,21]$ as shown in Figure 2.

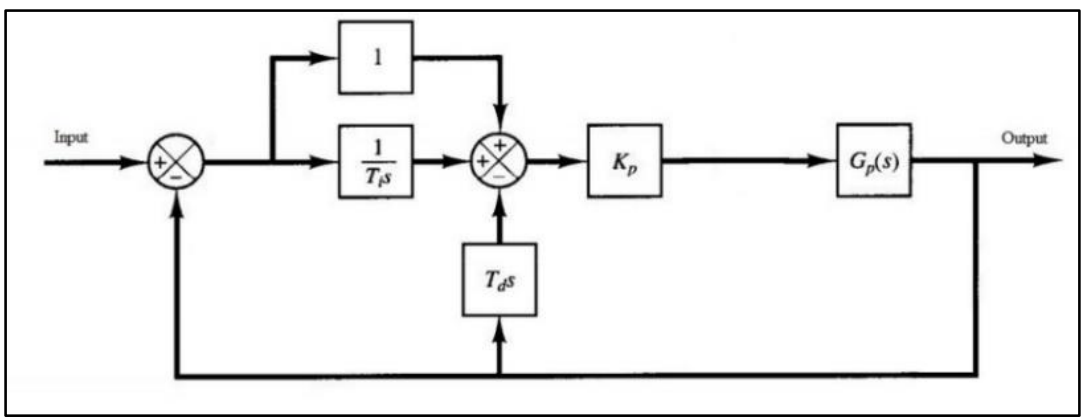

Figure 2. PI-D controller [21]

Transfer function of it $=k_{p}\left(1+\frac{1}{T_{i} S}\right) * \frac{\mathrm{G}}{\left[1+\left[k_{p}\left(1+\frac{1}{T_{i} S}+T_{d} s\right)\right] \mathrm{G}\right.}$

I-PD controller is rearrangement the connection of PID elements, also. The P and D parts of the PID are connected with the feedback path. The influence of these parts will be on feedback path only [21]. As shown in Figure 3. 


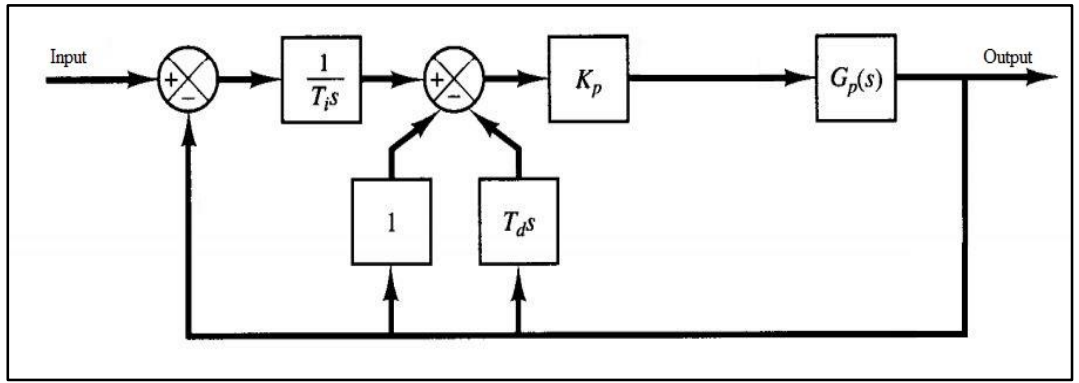

Figure 3. I-PD controller [21]

Transfer function of it $=k_{p}\left(\frac{1}{T_{i} s}\right) * \frac{\mathrm{G}}{\left[1+\left[k_{p}\left(1+\frac{1}{T_{i} S}+T_{d} S\right)\right] \mathrm{G}\right.}$

In the section two of this paper, modeling of DC motor will be presented. The response of the DC motor with variant controllers and unity feedback control system will be discussed in the other sections. When it is with unity feedback control system, the approach will be studied in section three. When it is with conventional PID controller, the approach will be studied in section four. There are two parts in the section five. Part one discusses the approach of using it with modification PID controller, PI-D controller. Part two discusses the approach of using it with modification PID controller, I-PD controller. The section six will present the comparison. The section seven will present the conclusion.

\section{MODELING OF DC MOTOR}

The Figure 4 illustrates the circuit of direct current motor, DC motor [1].

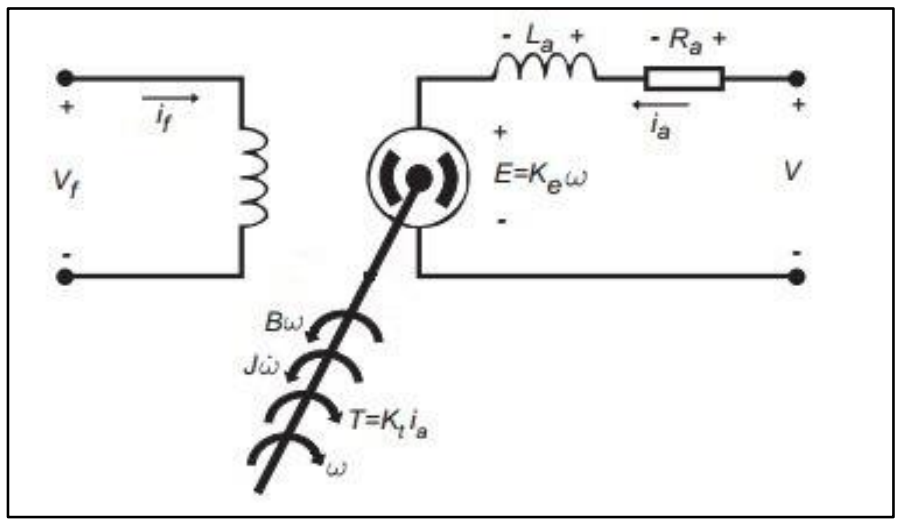

Figure 4. DC motor circuit [1]

The mathematical equations of DC motor can be written [1, 14, 18, 22-25]:

$$
\begin{aligned}
& \mathrm{V}=R_{a} i_{a}+L_{a} \frac{d i_{a}}{d t}+\mathrm{E} \\
& \mathrm{E} \propto \Phi \omega \\
& \mathrm{E}=\mathrm{k} \Phi \omega=k_{t} \omega \\
& \omega=\frac{d \theta}{d t} \\
& \mathrm{E}=k_{t} \frac{d \theta}{d t} \\
& \mathrm{~T} \propto \Phi i_{a}=k_{1} \Phi i_{a} \\
& \mathrm{~T}=k_{t} i_{a}
\end{aligned}
$$


Mechanical torque equation is

$$
\mathrm{T}=\mathrm{J} \frac{d^{2} \theta}{d t^{2}}+\mathrm{B} \frac{d \theta}{d t}
$$

The parameters of the DC motor can be defined.

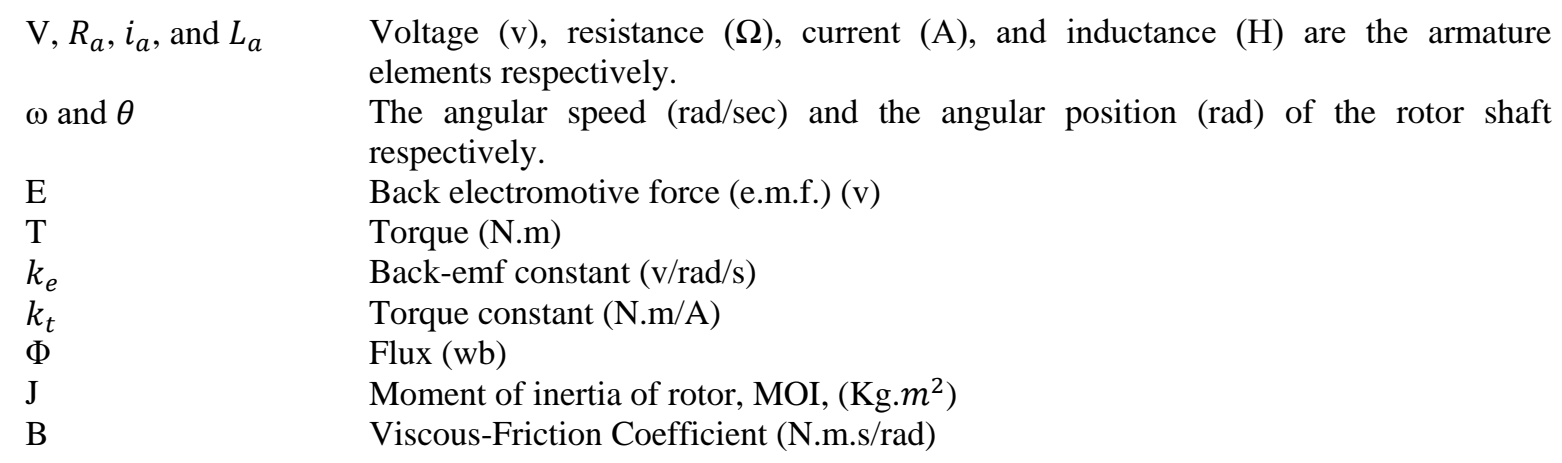

The Laplace transforms for the (1), (2), (3), and (4) and their block diagrams can be obtained:

$$
\begin{aligned}
& \mathrm{V}(\mathrm{s})=R_{a} I_{a}(s)+L_{a} S I_{a}(s)+\mathrm{E}(\mathrm{s}) \\
& \mathrm{V}(\mathrm{s})-\mathrm{E}(\mathrm{s})=R_{a} I_{a}(s)+L_{a} S I_{a}(s) \\
& \mathrm{E}=k_{t} S \theta(\mathrm{s}) \\
& \mathrm{T}(\mathrm{s})=k_{t} I_{a}(s) \\
& \mathrm{T}=\mathrm{J} S^{2} \theta(\mathrm{s})+\mathrm{B} S \theta(\mathrm{s}) \\
& \mathrm{T}(\mathrm{s})=S \theta(\mathrm{s})(\mathrm{JS}+\mathrm{B})
\end{aligned}
$$$$
\mathrm{V}(\mathrm{s})-\mathrm{E}(\mathrm{s})=R_{a} I_{a}(s)+L_{a} S I_{a}(s)
$$

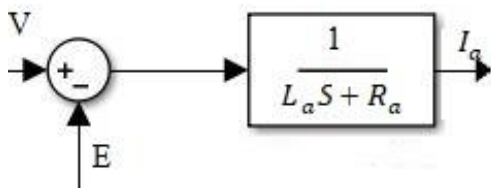
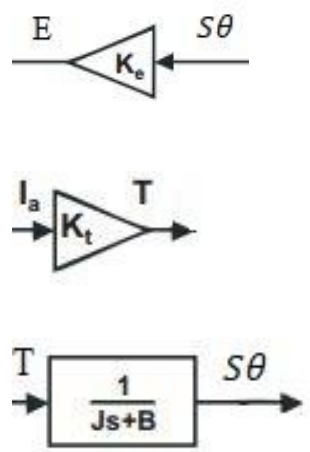

The Figure 5 illustrates the direct current motor block diagram:

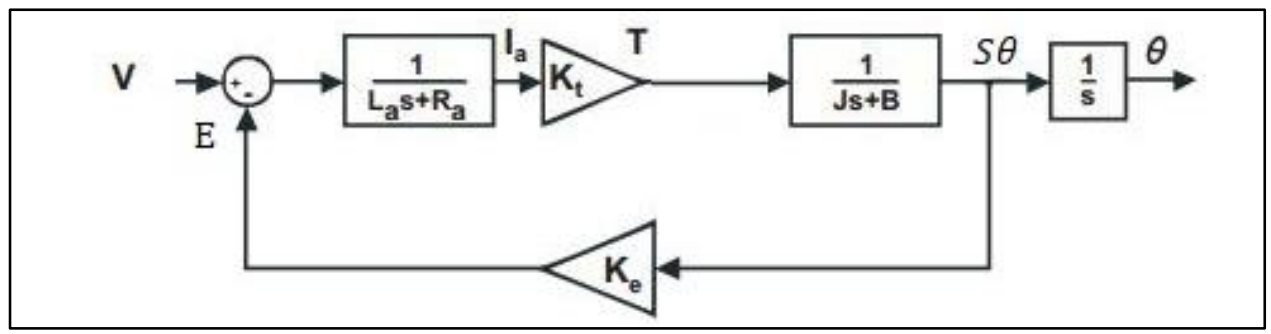

Figure 5. Direct Current motor block diagram [1, 14]

$$
\mathrm{G}=\frac{\theta}{V}=\frac{K_{t}}{L_{a} J S^{3}+\left(R_{a} J+B L_{a}\right) S^{2}+\left(R_{a} B+K_{t} K_{e}\right) S}
$$

$\mathrm{G}$ is the DC motor transfer function. $\mathrm{V}$ and $\theta$ are the input and output repectively. 


\section{RESPONSE OF ANGULAR POSITION OF THE ROTOR OF THE DC MOTOR WITH UNITY FEEDBACK CONTROL SYSTEM}

To study the response of the DC motor, a unity feedback control system is used with the DC motor. The input is a unit step function while the scope is used to get the response. By using Matlab program, the time domain specifications of the transient response and the response figure can be obtained. The Figure 6 illustrates its block diagram.

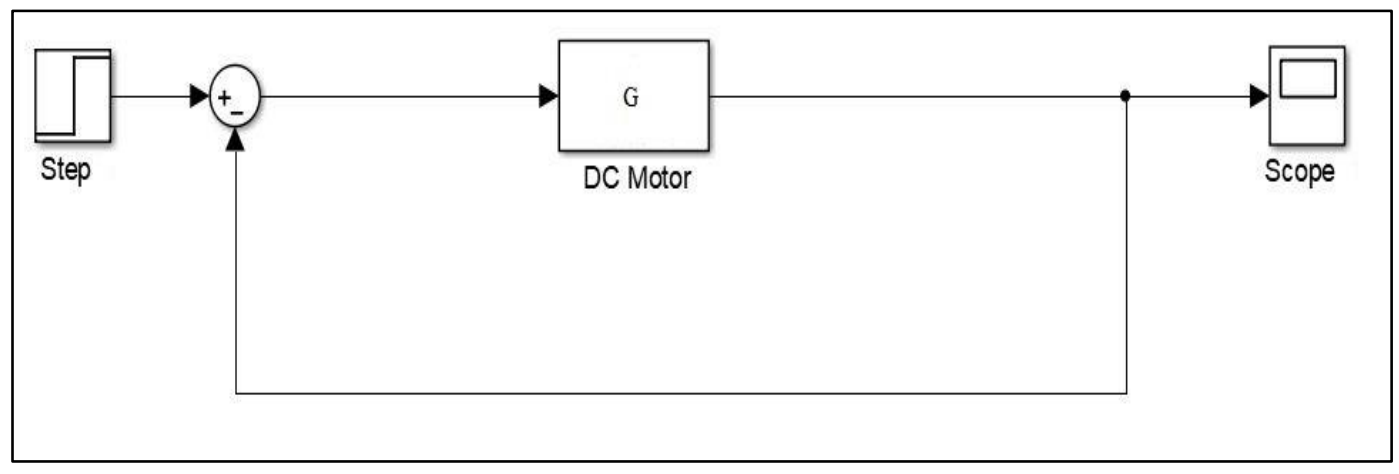

Figure 6. The control system of the DC motor

The system transfer function is

$$
\mathrm{TF}=\frac{G}{1+G}=\frac{K_{t}}{L_{a} J S^{3}+\left(R_{a} J+B L_{a}\right) S^{2}+\left(R_{a} B+K_{t} K_{e}\right) S+K_{t}}
$$

The parameters values of DC motor were obtained from the paper of [1]. They summarized the parameters' results for three attempts in a Table 2 . The average values of these readings are used in this paper as shown in Table 3.

Table 2.Parameters of DC motor [1]

\begin{tabular}{cccc}
\hline Parameters & $1^{\text {st }}$ case & $2^{\text {nd }}$ case & $3^{\text {rd }}$ case \\
\hline B $(\mathrm{N} . \mathrm{m} . \mathrm{s})$ & 0.041202 & 0.043926 & 0.0428167 \\
$\mathrm{~J}\left(\mathrm{Kg} \cdot \mathrm{m}^{2}\right)$ & 0.057419 & 0.044042 & 0.03188 \\
$k_{e}(\mathrm{~V} / \mathrm{rad} / \mathrm{s})$ & 1.835 & 1.8074 & 1.8674 \\
$k_{t}(\mathrm{~N} . \mathrm{m} / \mathrm{A})$ & 1.835 & 1.8074 & 1.8674 \\
$L_{a}(\mathrm{H})$ & 0.10419 & 0.1044227 & 0.104305 \\
$R_{a}(\Omega)$ & 3.0484 & 3.04325 & 3.045653 \\
\hline
\end{tabular}

Table 3. The Average values of the parameters

\begin{tabular}{cc}
\hline Parameters & Average \\
\hline $\mathrm{B}(\mathrm{N} . \mathrm{m} . \mathrm{s})$ & 0.042648233 \\
$\mathrm{~J}\left(\mathrm{Kg} \cdot \mathrm{m}^{2}\right)$ & 0.044447 \\
$k_{e}(\mathrm{~V} / \mathrm{r} \mathrm{ad} / \mathrm{s})$ & 1.8366 \\
$k_{t}(\mathrm{~N} . \mathrm{m} / \mathrm{A})$ & 1.8366 \\
$L_{a}(\mathrm{H})$ & 0.1043059 \\
$R_{a}(\Omega)$ & 3.045767667 \\
\hline
\end{tabular}

$$
\begin{aligned}
& \mathrm{TF}=\frac{G}{1+G}=\frac{K_{t}}{L_{a} J S^{3}+\left(R_{a} J+B L_{a}\right) S^{2}+\left(R_{a} B+K_{t} K_{e}\right) S+K_{t}} \\
& \mathrm{TF}=\frac{1.8366}{0.004636 S^{3}+0.1398 S^{2}+3.503 S+1.8366}
\end{aligned}
$$

The response was got by using Matlab when a unit step function is applied as shown in Figure 7. The time domain values of this case were acquired as shown in Table 4 


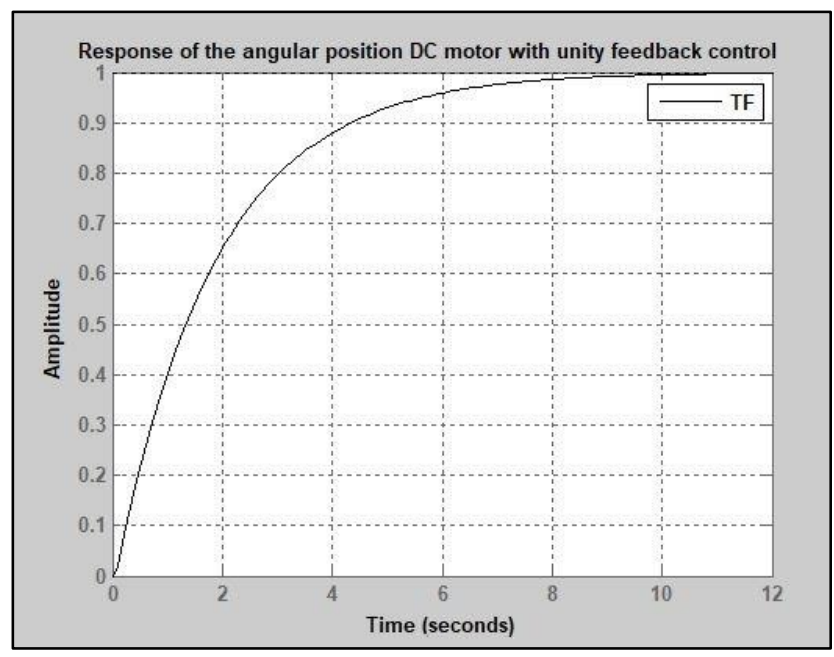

Figure 7. Response of the angular position DC motor with unity feedback control system

Table 4. Time domain specifications values of the DC motor with unity feedback control system

\begin{tabular}{cc}
\hline Time Domain Specifications & Value \\
\hline Rise time (seconds) & 4.1034 \\
Settling time (seconds) & 7.3451 \\
Overshoot (\%) & 0 \\
Peak (Amplitude unit) & 0.9993 \\
Peak time (seconds) & 13.6726 \\
\hline
\end{tabular}

\section{RESPONSE OF ANGULAR POSITION OF THE ROTOR OF DC MOTOR WITH} CONVENTIONAL PID CONTROLLER

By adding PID controller to the system, the block diagram will be illustrated in the Figure 8.

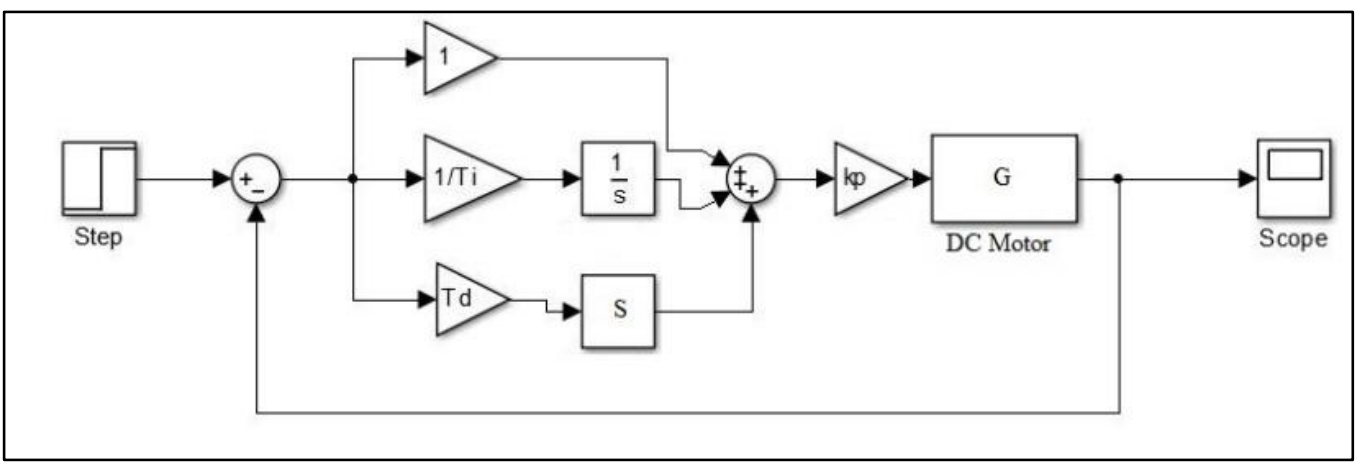

Figure 8. PID controller with DC motor

$$
\begin{aligned}
& \text { Let } G_{c}=\mathrm{PID}=k_{p}\left(1+\frac{1}{T_{i} S}+T_{d} s\right) \\
& \mathrm{TF}_{2}=\frac{G G_{c}}{1+G G_{c}}
\end{aligned}
$$

$\mathrm{TF}_{2}$ : Transfer function of the DC motor with conventional PID controller

$$
\mathrm{TF}_{2}=k_{p}\left(1+\frac{1}{T_{i} S}+T_{d} S\right)^{*} \frac{\frac{K_{t}}{L_{a} J S^{3}+\left(R_{a} J+B L_{a}\right) S^{2}+\left(R_{a} B+K_{t} K_{e}\right) S}}{\left[1+\left[k_{p}\left(1+\frac{1}{T_{i} S}+T_{d} S\right)\right] \frac{K_{t}}{L_{a} J S^{3}+\left(R_{a} J+B L_{a}\right) S^{2}+\left(R_{a} B+K_{t} K_{e}\right) S}\right]}
$$




$$
\mathrm{TF}_{2}=k_{p}\left(1+\frac{1}{T_{i} S}+T_{d} S\right) * \frac{K_{t}}{\left[L_{a} J S^{3}+\left(R_{a} J+B L_{a}\right) S^{2}+\left(R_{a} B+K_{t} K_{e}\right) S\right]+K_{t} k_{p}\left(1+\frac{1}{T_{i} S}+T_{d} S\right)}
$$

Using the Z-N second method in the paper is to adjust the elements of PID controller. Put $T_{i}=\infty$ and $T_{d}=0$ and substitute these values in the (8).

$$
\mathrm{TF}_{\mathrm{ZN}}=\frac{K_{t} K_{p}}{L_{a} J S^{3}+\left(R_{a} J+B L_{a}\right) S^{2}+\left(R_{a} B+K_{t} K_{e}\right) S+K_{t} K_{p}}
$$

$\mathrm{TF}_{\mathrm{ZN}}$ : Transfer function of the DC Motor with Conventional PID Controller when Ziegler Nichols Method is used

By using Routh Hurwitz Criterion to find the $K_{p}$ value

$$
\begin{array}{lll}
S^{3} & L_{a} J & \left(R_{a} B+K_{t} K_{e}\right) \\
S^{2} & \left(R_{a} J+B L_{a}\right) & K_{t} K_{p} \\
S & \left(R_{a} B+K_{t} K_{e}\right)-\frac{L_{a} J K_{t}{ }^{K}{ }_{p}}{\left(R_{a} J+B L_{a}\right)} & 0 \\
S^{0} & K_{t} K_{p} & 0 \\
\left(R_{a} B+K_{t} K_{e}\right)-\frac{L_{a} J K_{t} K_{p}}{\left(R_{a} J+B L_{a}\right)}=0 & \\
K_{p}=\frac{\left(R_{a} B+K_{t} K_{e}\right)\left(R_{a} J+B L_{a}\right)}{L_{a} J K_{t}} &
\end{array}
$$

By substituting the values of the Table 3 in the (10), $K_{p}=57.5247$

By examining the coefficients of the first column, the sustained oscillation will occur when $K_{p}=57.5247$. Thus the critical gain $K_{c r}$ will be 57.5247 .

With gain $K_{p}$ set equal $K_{c r}=57.5247$, the characteristic equation of $\mathrm{TF}_{\mathrm{ZN}}$ will be

$$
L_{a} J S^{3}+\left(R_{a} J+B L_{a}\right) S^{2}+\left(R_{a} B+K_{t} K_{e}\right) S+57.5247 K_{t}=0
$$
equation.

The frequency of the sustained oscillation can be obtained by substituting $S=j \omega$ in the characteristic

$$
\begin{aligned}
& L_{a} J(j \omega)^{3}+\left(R_{a} J+B L_{a}\right)(j \omega)^{2}+\left(R_{a} B+K_{t} K_{e}\right) j \omega+57.5247 K_{t}=0 \\
& -\left(R_{a} J+B L_{a}\right) \omega^{2}+57.5247 K_{t}=0 \\
& \omega^{2}=\frac{57.5247 K_{t}}{\left(R_{a} J+B L_{a}\right)}=755.5937 \\
& \omega=27.4881 \mathrm{rad} / \mathrm{sec}
\end{aligned}
$$

Therefore, the critical period $\left(P_{c r}\right)$ can be obtained.

$$
P_{c r}=\frac{2 \pi}{\omega}=0.2286 \text { second }
$$

$k_{p}, T_{i}$, and $T_{d}$ can be obtained from Ziegler Nichols Second Method table, Table 1.

$$
\begin{aligned}
& k_{p}=0.6 K_{c r}=34.5148 \\
& T_{i}=0.5 P_{c r}=0.1143 \mathrm{sec} \\
& T_{d}=0.125 P_{c r}=0.0286 \mathrm{sec}
\end{aligned}
$$

The parameters of PID controller are available now, and it is going to be tuned by them. 
Getting the transfer function of the DC motor with PID controller can be done by returning back to (8) (the $\mathrm{TF}_{2}$ equation) and substituting the PID parameters and the values of Table 3 . The response can be got by using Matlab when a unit step function is applied as shown in Figure 9. Time domain values of this case are acquired Table 5 .

$$
\begin{aligned}
& \mathrm{TF}_{2}=k_{p}\left(1+\frac{1}{T_{i} S}+T_{d} S\right) * \frac{K_{t}}{\left[L_{a} J S^{3}+\left(R_{a} J+B L_{a}\right) S^{2}+\left(R_{a} B+K_{t} K_{e}\right) S\right]+K_{t} k_{p}\left(1+\frac{1}{T_{i} S}+T_{d} S\right)} \\
& \mathrm{TF}_{2}=\frac{k_{t} k_{p} T_{i} T_{d} S^{2}+k_{t} k_{p} T_{i} S+k_{t} k_{p}}{L_{a} J T_{i} S^{4}+\left(R_{a} J+B L_{a}\right) T_{i} S^{3}+\left(R_{a} B+k_{t} k_{e}+k_{t} k_{p} T_{d}\right) T_{i} S^{2}+k_{t} k_{p} T_{i} S+k_{t} k_{p}} \\
& \mathrm{TF}_{2}=\frac{0.207 S^{2}+7.245 S+63.39}{0.0005299 S^{4}+0.01598 S^{3}+0.6074 S^{2}+7.245 S+63.39}
\end{aligned}
$$

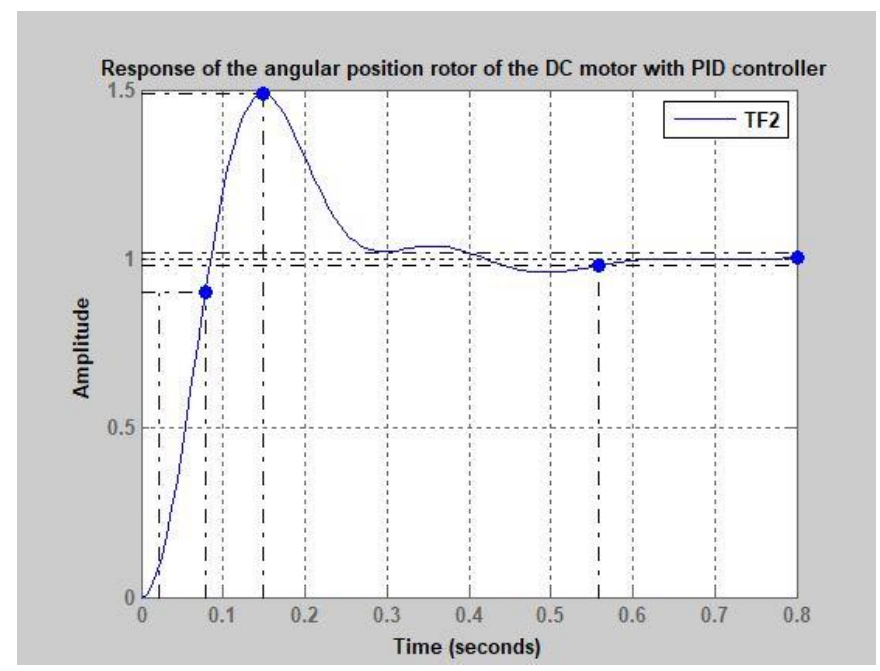

Figure 9. Response of the angular position of the DC motor rotor with PID controller

Table 5. Time domain specifications values of the DC motor with PID controller

\begin{tabular}{cc}
\hline Time Domain Specifications & Value \\
\hline Rise time (seconds) & 0.0559 \\
Settling time (seconds) & 0.5574 \\
Overshoot (\%) & 48.7302 \\
Peak (Amplitude unit) & 1.4873 \\
Peak time (seconds) & 0.1496 \\
\hline
\end{tabular}

\section{RESPONSE OF THE ANGULAR POSITION OF THE ROTOR OF DC MOTOR WITH MODIFICATIONS PID CONTROLLER}

\subsection{Using PI-D controller}

By adding PI-D controller to the system, the block diagram will be illustrated in the Figure 10.

$$
\begin{aligned}
& \mathrm{TF}_{3}=k_{p}\left(1+\frac{1}{T_{i} S}\right) * \frac{\frac{K_{t}}{L_{a} J S^{3}+\left(R_{a} J+B L_{a}\right) S^{2}+\left(R_{a} B+K_{t} K_{e}\right) S}}{\left[1+\left[k_{p}\left(1+\frac{1}{T_{i} S}+T_{d} S\right)\right] \frac{K_{t}}{L_{a} J S^{3}+\left(R_{a} J+B L_{a}\right) S^{2}+\left(R_{a} B+K_{t} K_{e}\right) S}\right]} \\
& \mathrm{TF}_{3}=k_{p}\left(1+\frac{1}{T_{i} S}\right) * \frac{K_{t}}{\left[L_{a} J S^{3}+\left(R_{a} J+B L_{a}\right) S^{2}+\left(R_{a} B+K_{t} K_{e}\right) S\right]+K_{t} k_{p}\left(1+\frac{1}{T_{i} S}+T_{d} S\right)} \\
& \mathrm{TF}_{3}=\frac{k_{t} k_{p} T_{i} S+k_{t} k_{p}}{L_{a} J T_{i} S^{4}+\left(R_{a} J+B L_{a}\right) T_{i} S^{3}+\left(R_{a} B+k_{t} k_{e}+k_{t} k_{p} T_{d}\right) T_{i} S^{2}+k_{t} k_{p} T_{i} S+k_{t} k_{p}}
\end{aligned}
$$

$\mathrm{TF}_{3}$ : Transfer function of DC motor with modification PI-D controller 
$\mathrm{TF}_{3}$ can be got by using the readings of Table and the same values of tuning parameters, which is used in the conventional PID controller. The response can be got by using Matlab when a unit step function is applied as shown in Figure 11. Time domain values of this case are obtained as shown in Table 6.

$$
\mathrm{TF}_{3}=\frac{7.245 S+63.39}{0.0005299 S^{4}+0.01598 S^{3}+0.6074 S^{2}+7.245 S+63.39}
$$

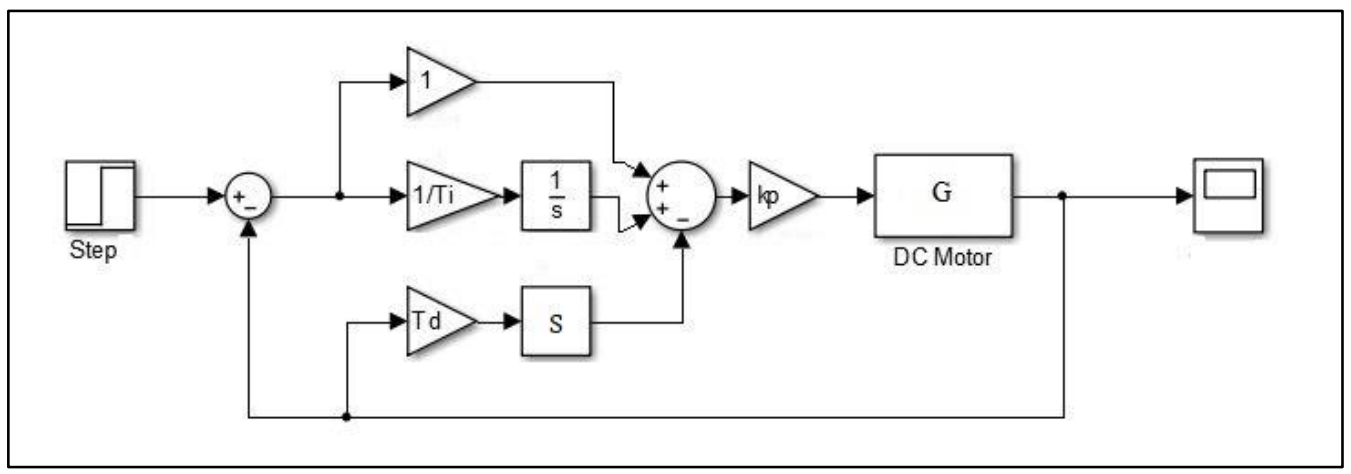

Figure 10. PI-D controller with DC motor

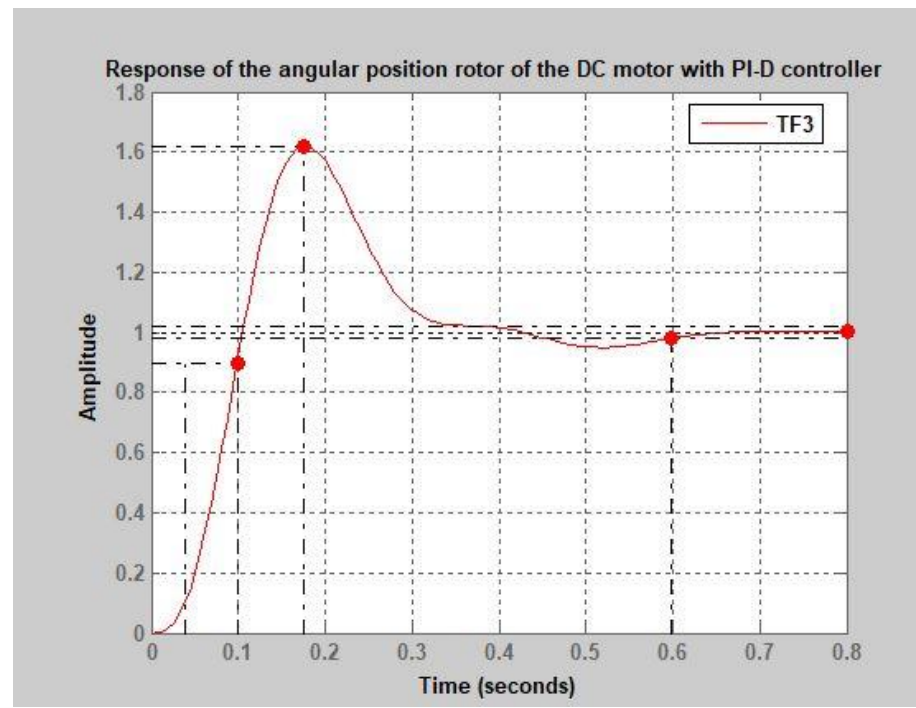

Figure 11. Response of the angular position of the DC motor rotor with PI-D controller

Table 6. Time domain specifications values of the DC Motor with PI-D controller

\begin{tabular}{cc}
\hline Time Domain Specifications & Value \\
\hline Rise time (seconds) & 0.0603 \\
Settling time (seconds) & 0.5987 \\
Overshoot (\%) & 61.8369 \\
Peak (Amplitude unit) & 1.6184 \\
Peak time (seconds) & 0.1745 \\
\hline
\end{tabular}

\subsection{Using I-PD controller}

By adding I-PD controller to the system, the block diagram will be illustrated in the Figure 12.

$$
\mathrm{TF}_{4}=k_{p}\left(\frac{1}{T_{i} S}\right) * \frac{\frac{K_{t}}{L_{a} J S^{3}+\left(R_{a} J+B L_{a}\right) S^{2}+\left(R_{a} B+K_{t} K_{e}\right) S}}{\left[1+\left[k_{p}\left(1+\frac{1}{T_{i} S}+T_{d} S\right)\right] \frac{K_{t}}{L_{a} J S^{3}+\left(R_{a} J+B L_{a}\right) S^{2}+\left(R_{a} B+K_{t} K_{e}\right) S}\right]}
$$




$$
\begin{aligned}
& \mathrm{TF}_{4}=k_{p}\left(\frac{1}{T_{i} S}\right) * \frac{K_{t}}{\left[L_{a} J S^{3}+\left(R_{a} J+B L_{a}\right) S^{2}+\left(R_{a} B+K_{t} K_{e}\right) S\right]+K_{t} k_{p}\left(1+\frac{1}{T_{i} S}+T_{d} S\right)} \\
& \mathrm{TF}_{4}=\frac{k_{t} k_{p}}{L_{a} J T_{i} S^{4}+\left(R_{a} J+B L_{a}\right) T_{i} S^{3}+\left(R_{a} B+k_{t} k_{e}+k_{t} k_{p} T_{d}\right) T_{i} S^{2}+k_{t} k_{p} T_{i} S+k_{t} k_{p}}
\end{aligned}
$$

$\mathrm{TF}_{4}: \quad$ Transfer function of DC Motor with Modification I-PD Controller

$\mathrm{TF}_{4}$ can be got by using the readings of Table 3 and the same values of tuning parameters, which is used in the conventional PID controller. The response can be got by using Matlab when a unit step function is applied as shown in Figure 13. Time domain values of this case are obtained as shown in Table 7.

$$
\mathrm{TF}_{4}=\frac{63.39}{0.0005299 S^{4}+0.01598 S^{3}+0.6074 S^{2}+7.245 S+63.39}
$$

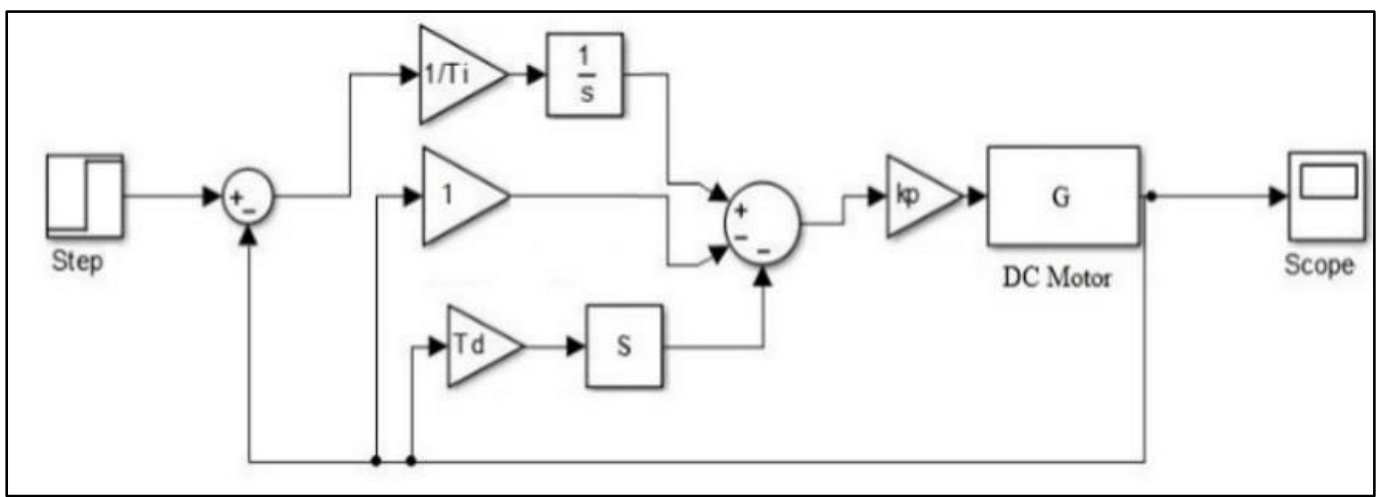

Figure 12. I-PD controller with DC motor

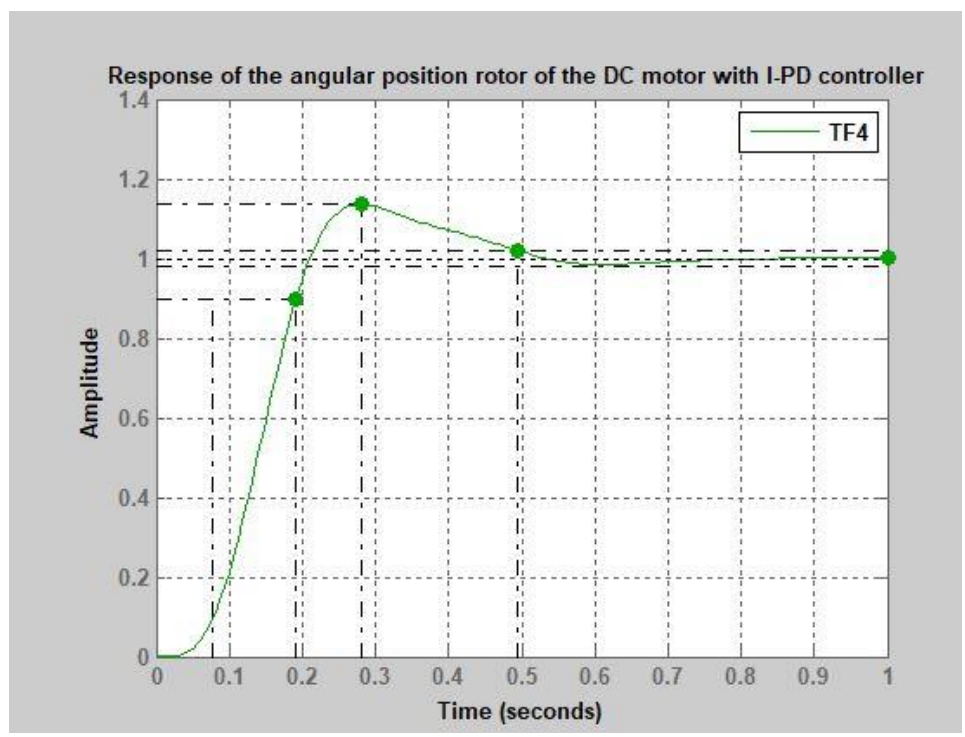

Figure 13. Response of the angular position of the DC motor rotor with I-PD controller

Table 7. Time domain specifications values of the DC motor with I-PD controller

\begin{tabular}{cc}
\hline Time Domain Specifications & Value \\
\hline Rise time (seconds) & 0.1133 \\
Settling time (seconds) & 0.4941 \\
Overshoot (\%) & 13.7059 \\
Peak (Amplitude unit) & 1.1371 \\
Peak time (seconds) & 0.2805 \\
\hline
\end{tabular}




\section{THE COMPARISON}

The comparison between the DC motor angular position with unity feedback control system and with conventional PID and modification PID controllers are obtained from the Table 8 and Figure 14 (see appendix) in Appendix. Each case of the DC motor response curves is represented by colors. The black represents the response of it with unity feedback control system. The blue represents the response of it with conventional PID controller. The red represents the response of it with modification PI-D controller. The green curve represents the response of it with modification I-PD controller.

The Figures 14 (a-d) illustrates the response of DC motor and conventional PID controller, DC motor and PI-D controller, DC motor and I-PD controller, and DC motor and all controllers respectively. The Figures 14 (e-h) illustrates the response of conventional PID and PI-D controllers, conventional PID and I-PD controllers, PI-D and I-PD controllers, all controllers respectively.

The controller that gives less rise time and less peak time is conventional PID controller, PI-D controller, and I-PD controller respectively. However, the controller that gives less settling time and less maximum overshoot is I-PD, conventional PID controller, and PI-D controller respectively. The best controller that gives most reasonable readings is the modification I-PD controller, but the designer can decide which the controller is the best depending on his needs. The I-PD controller is the best because it has less settling time and less maximum overshoot. Furthermore, it has a few parts of second difference in rise time and peak time with conventional PID controller and I-PD controller.

Table 8. Time domain specifications values of the DC motor for four cases

\begin{tabular}{ccccc}
\hline Time Domain & With unity feedback & Conventional PID & \multicolumn{2}{c}{ Modifications of PID Controllers } \\
Specifications & control system & Controller & PI-D & I-PD \\
\hline Rise time(seconds) & 4.1034 & 0.0559 & 0.0603 & 0.1133 \\
Settling time(seconds) & 7.3451 & 0.5574 & 0.5987 & 0.4941 \\
Overshoot (\%) & 0 & 48.7302 & 61.8369 & 13.7059 \\
Peak(Amplitude unit) & 0.9993 & 1.4873 & 1.6184 & 1.1371 \\
Peak time(seconds) & 13.6726 & 0.1496 & 0.1745 & 0.2805 \\
\hline
\end{tabular}

\section{CONCLUSION}

An analytical study were presented in this paper for four cases of step response angular position of the rotor of DC motor. The cases are step response with unity feedback control system, step response with conventional PID controller, step response with PI-D controller, and step response with I-PD controller. The time domain specifications for each case was acquired. Also, the response for each one can be got by using Matlab. The Z-N $2^{\text {nd }}$ method was used for tuning the variants PID controllers. The performance comparison for the four cases was done depending on the readings and curves from the Matlab. The best controller was determined depending on the comparison. The controller that gives the good specification is the best.

\section{APPENDIX}

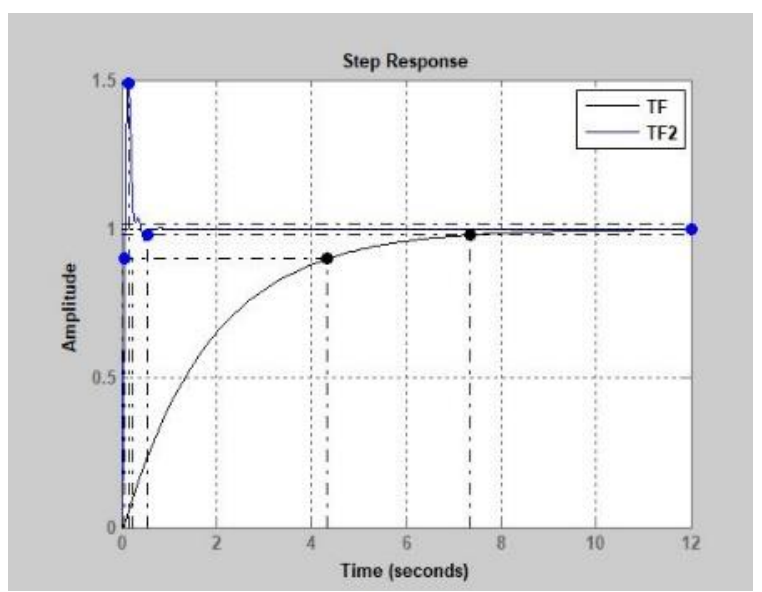

(a)

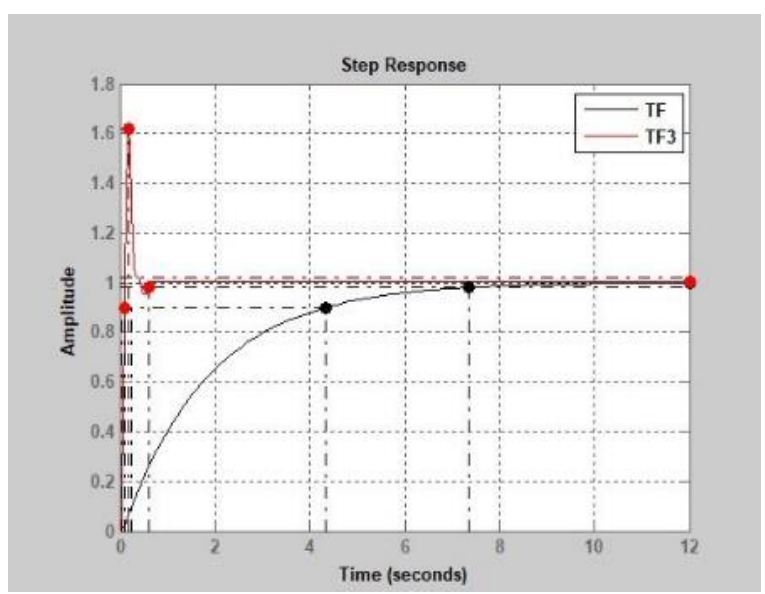

(b)

Figure 14. Response of angular position DC motor rotor with and without controllers 


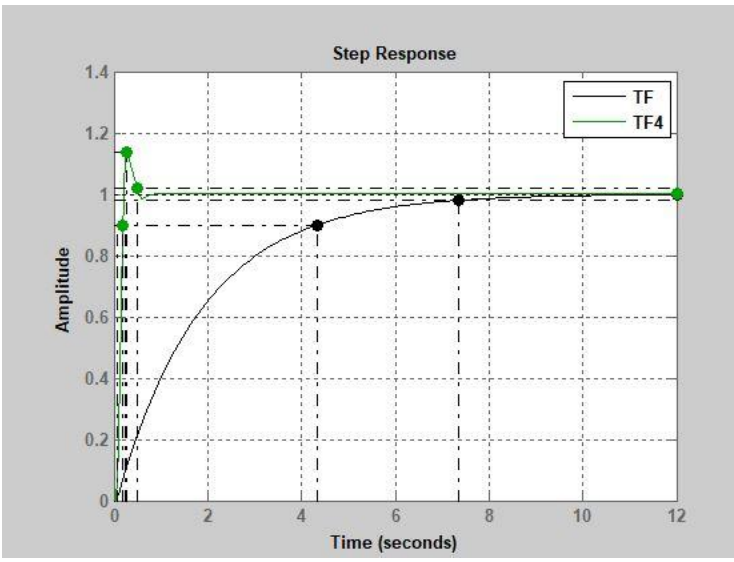

(c)

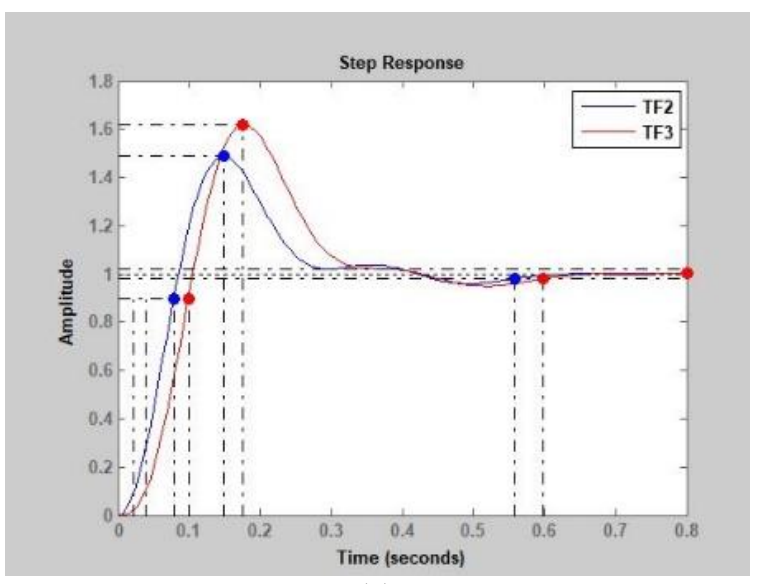

(e)

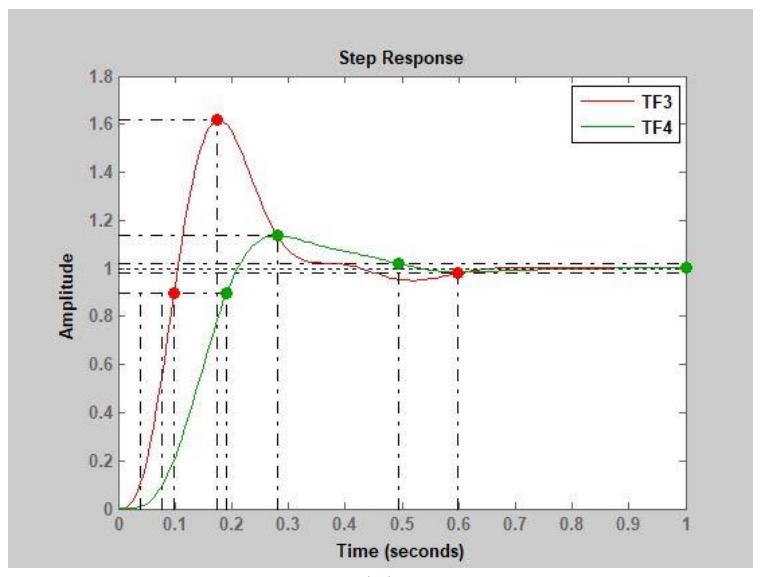

(g)

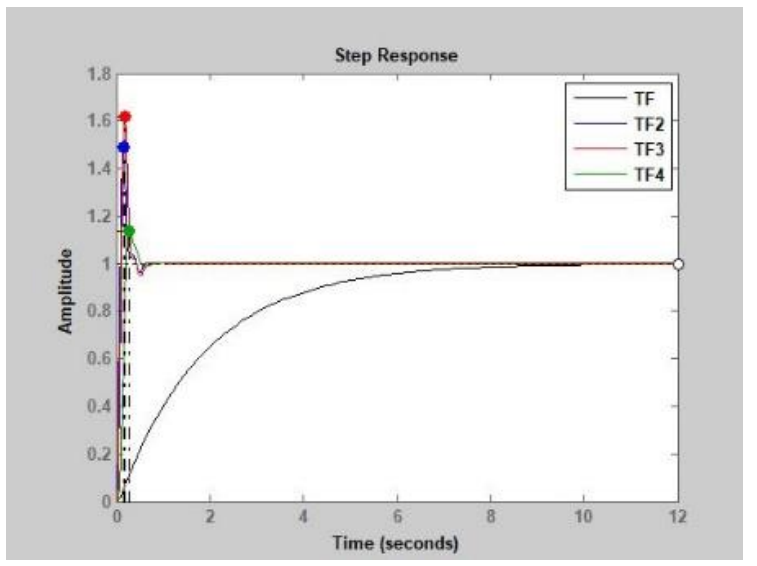

(d)

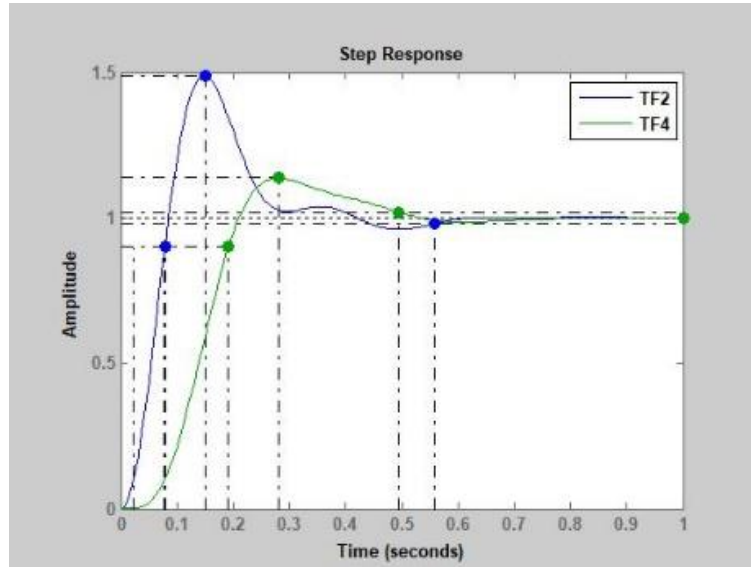

(f)

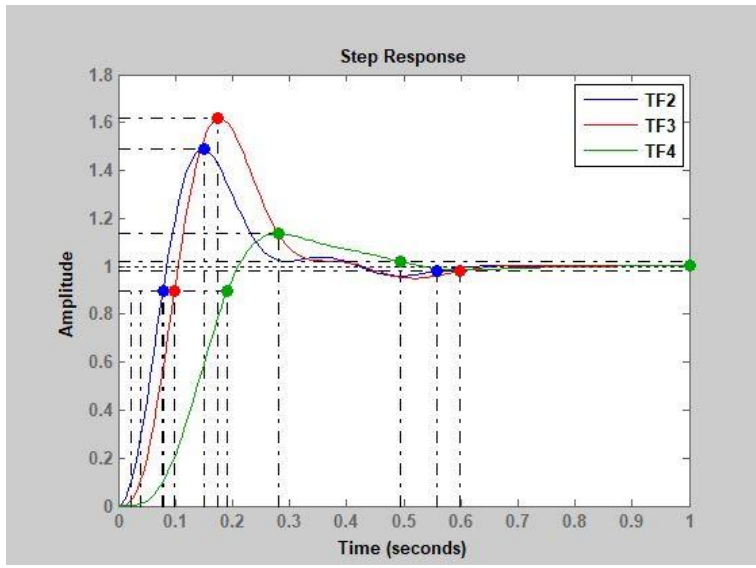

(h)

Figure 14. Response of angular position DC Motor rotor with and without controllers (continue)

\section{REFERENCES}

[1] M. S. Salah and M. Abdelati, "Parameters Identification Of A Permanent Magnet DC Motor," ACTA Press, 2010.

[2] M. A. Shamseldin and A. A. EL-Samahy, "Speed Control of BLDC Motor By Using PID Control and Self-tuning Fuzzy PID Controller," 15th International Workshop on Research and Education in Mechatronics, pp. 1-9, 2014.

[3] S. N. Al-Bargothi, G. M. Qaryouti and Q. M. Jaber, "Speed control of DC motor using conventional and adaptive PID controllers," Indonesian Journal of Electrical Engineering and Computer Science (IJEECS), vol. 16, no. 3, pp. 1221-1228, 2019.

[4] M. Ahmad and R. Ismail, "A data-driven sigmoid-based PI controller for buck-converter powered dc motor," IEEE Symposium on Computer Applications \& Industrial Electronics (ISCAIE), pp. 81-86, 2017. 
[5] M. I. F. M. Hanif, M. H. Suid and . M. A. Ahmad, "A piecewise affine PI controller for buck converter generated DC motor," International Journal of Power Electronics and Drive System, vol. 10, no. 3, pp. 1419-1426, 2019.

[6] Jayanthi. V, Sowmithra. R. V and S. Kumar, "Buck Converter Based Starter and Speed Controller for a DC Motor using PID Controller," IJIRST -International Journal for Innovative Research in Science \& Technology, vol. 1, no. 12 , pp. 354-358, 2015.

[7] M. Ahmad, R. Raja Ismail and M. Ramli, "Control Strategy of Buck Converter Driven Dc Motor: a Comparative Assessment," Australian Journal of Basic and Applied Sciences, vol. 4, no. 10, pp. 4893-4903, 2010.

[8] M. Z. Fadel, M. G. Rabie and A. M. Youssef, "Modeling, Simulation and Control of a Fly-by-wire Flight Control System Using Classical PID and Modified PI-D Controllers," International Information and Engineering Technology Association (IIETA), vol. 52, no. 3, pp. 267-276, 2019.

[9] P. R. Hemavathy, S. Y. Mohamed and S. K. Lakshmanaprabu, "Internal model controller based PID with fractional filter design for a nonlinear process," International Journal of Electrical and Computer Engineering (IJECE), vol. 10, no. 1, pp. 243-254, 2020.

[10] A. Deshmukh and S. R. Vaishnav, "A Comparative Performance Analysis of PID Tuning Techniques Based On Frequency Response Specification," Second International Conference on Emerging Trends in Engineering \& Technology, pp. 971-974, 2009.

[11] B. Nagaraj, S. Subha and B. Rampriya, "Tuning Algorithms for PID Controller Using Soft Computing Techniques," International Journal of Computer Science and Network Security, vol. 8, no. 4, pp. 278-281, 2008.

[12] A. A. Emhemed and R. B. Mamat, "Modelling and Simulation for Industrial DC Motor Using Intelligent Control," International Symposium on Robotics and Intelligent Sensors (IRIS 2012), vol. 41, pp. 420-425, 2012.

[13] M. M. Maung, M. M. Latt and C. M. Nwe, "DC Motor Angular Position Control using PID Controller with Friction Compensation," International Journal of Scientific and Research Publications, vol. 8, no. 11, pp. 149-155, 2018.

[14] K. Sailan and K.-D. Kuhnert, "DC Motor Angular Position Control using PID Controller for the porpuse of controlling the Hydraulic Pump," International Conference on Control, Engineering \& Information Technology (CEIT'13), pp. 2-6, 2013.

[15] S. Bharadwaj, "Comparative Analysis of Speed Control Techniques of DC Motors with Matlab," International Journal of Engineering Research \& Technology (IJERT), vol. 4, no. 5, pp. 672-675, 2015.

[16] A. A. Hassan, N. K. Al-Shamaa and K. K. Abdalla, "Comparative Study for DC Motor Speed Control Using PID Controller," International Journal of Engineering and Technology (IJET), vol. 9, no. 6, pp. 4181-4192, 2018.

[17] M. R. Khan, A. A. Khan and U. Ghazali, "Speed Control of DC Motor under Varying Load Using PID Controller," International Journal of Engineering (IJE), vol. 9, no. 3, pp. 38-48, 2015.

[18] A. A. Hassan, N. K. Al-Shamaa and K. K. Abdalla, "Comparative Study of Conventional and Optimal PID Tunned Methods for PMDCM Speed Control," International Journal of Applied Engineering Research, vol. 12, no. 24, pp. 15999-16007, 2017.

[19] S. Al Nisa, L. Mathew and S. Chatterji, "Comparative Analysis of Speed Control of DC Motor Using AI Technique," International Journal of Engineering Research and Applications, vol. 3, no. 3, pp. 1137-1146, 2013.

[20] A. Tepljakov, E. A. Gonzalez, E. Petlenkov, J. Belikov, C. A. Monje and I. Petráš, "Incorporation of fractionalorder dynamics into an existing PI/PID DC motor control loop," ISA transactions, vol. 60, pp. 262-273, 2016.

[21] K. Ogata, "Modern Control Engineering," River, NJ: Prentice-Hall, Inc., 1997.

[22] Z.-A. S. A. Rahman, "Design a Fuzzy Logic Controller for Controlling Position of D.C. Motor," International Journal of Computer Engineering In Research Trends (IJCERT), vol. 4, no. 7, pp. 285-289, 2017.

[23] B. Hekimoğlu, "Optimal tuning of fractional order PID controller for DC motor speed control via chaotic atom search optimization algorithm," IEEE Access, vol. 7, pp. 38100-38114, 2019.

[24] B. A. Obaid, A. L. Saleh and A. K. Kadhim, "Resolving of optimal fractional PID controller for DC motor drive based on anti-windup by invasive weed optimization technique," Indonesian Journal of Electrical Engineering and Computer Science (IJEECS), vol. 15, no. 1, pp. 95-103, 2019.

[25] W. M. Elsrogy, M. A. Fkirin and M. A. Moustafa Hassan, "Speed control of DC motor using PID controller based on artificial intelligence techniques," International Conference on Control, Decision and Information Technologies (CoDIT), 2013.

\section{BIOGRAPHY OF AUTHOR}

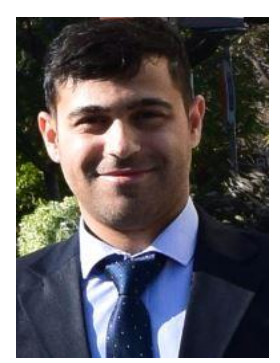

Mustafa A. Mhawesh earned his master's degree in Electrical Engineering from CSU, Fullerton, USA in 2017. He earned the B.Sc degree from AL-Furat Al-Awsat Technical University, Iraq 2011. The research interests are robotics and control systems. 